Article

\title{
An Investigation of What Factors Determine the Way in Which Customer Satisfaction Is Increased through Omni-Channel Marketing in Retail
}

\author{
Kamarin Merritt ${ }^{1}$ and Shichao Zhao ${ }^{2, *}$ \\ 1 Department of Computer and Information Sciences, Northumbria University, \\ Newcastle-upon-Tyne NE1 8ST, UK; kamarin.merritt@northumbria.ac.uk \\ 2 Department of Archaeology \& Anthropology, Bournemouth University, Fern Barrow, Poole, \\ Dorset BH12 5BB, UK \\ * Correspondence: szhao@bournemouth.ac.uk
}

Received: 3 September 2020; Accepted: 15 October 2020; Published: 30 October 2020

\begin{abstract}
There have been significant changes evident across the retail sector over the last 20 years, which have been primarily influenced by technological advancements. These changes have forced many retailers to rethink their business models and utilise a combination of both brick and mortar stores and online domains to present an integrated shopping experience. In order to gain an understanding of how customer satisfaction is increased through omni-channel retailing, we collected data through survey research, specifically through semi-structured interviews and questionnaires. In order to generate concise and accurate findings, the data were analysed using thematic analysis. From this analysis, three themes were generated. The first theme explores the reasoning behind preferred shopping methods and what influences these customers' purchase methods. The second theme explores customers' personal preference and investigates the potential of using virtual reality as a method for increasing customer satisfaction. Finally, the third theme looks into utilising interactive technology to create a diversified user experience. This theme explores the potential of utilising a communication platform for customers and also designing a tangible interface for disabled customers. This study has opened up an opportunity for future research and has outlined potential design insights in how to improve customer experience and customer purchase intentions.
\end{abstract}

Keywords: customer satisfaction; e-satisfaction; omni-channel retailing; value-sensitive design; thematic analysis (TA)

\section{Introduction and Executive Summary}

Significant changes have been evident across the retail sector over the last 20 years, primarily influenced through technological advancements that have transformed the experience of shopping both from a business perspective and from the customer point of engagement (Jain and Werth 2019). One of the main technological influences that has arisen as a result of this trend is 'Omni-channel Marketing', which is a unique way of shopping utilising a combination of both brick and mortar stores and online domains to present an integrated shopping experience that is totally reliant upon technology and that has contributed to rapid growth across the sector (Goyal 2017; Grewal et al. 2018). This technology has provided retailers with an extremely effective mechanism to increase and broaden their target markets through online segmentation, building customer relationships, offering a greater scale of product lines and delivering personalised customer offers. Customer responses have increased immensely following these innovations (Qazi et al. 2017), which can be seen in online sales growth for retailing organisations throughout the past decade (Office for National Statistics 2019b; Next Retail Ltd 2018). 
These changes have forced many retailers to rethink their business models and utilise a combination of both bricks and mortar stores and online domains to present an integrated omni-channel marketing model. The omni-channel is defined as the viewing experience through the eyes of the consumer, which is displayed in different ways across many channels (Melsted 2015). This term is becoming increasingly used within the business domain and by researchers in order to establish a foundation for understanding omni-channel marketing.

However, there is limited research around customers' perceptions of omni-channel marketing, thereby generating a need for further investigation as to whether this new approach being adopted by retailers can lead to increases in the satisfaction of their customers.

One of the largest UK retailers that has invested in changing their business model is Next PLC, which has 550 stores throughout the UK and employs over 40,000 staff (Ruddick, as cited in Ruddick 2014; Next Retail Ltd 2018). The staff numbers include not only store-based employees but also those who work solely in the online area of the business. Recent changes in sales results has provoked interest in this study due to the fact that Next PLC's online sales have now overtaken the sales from their traditional brick and mortar stores (Next Retail Ltd 2018). The retailing niche for Next PLC has seen a shift in culture that puts the emphasis more onto the domain of the Next PLC's online sales directory, which has overtaken the footfall in its stores-a trend that has also been seen for a substantive section of the whole retailing sector.

While satisfaction within stores can be evidenced through online reviews or Next PLC's very own Next Loves to Listen survey, online satisfaction, more recently known as 'e-satisfaction', is a domain that has been unexplored within the organisation. This has generated interest in understanding how customer satisfaction is ascertained through the use of omni-channel marketing within Next PLC. Understanding this will add to the knowledge base in this area.

This project analyses data of how the online presence of retailers (i.e., e-retailing) impacts on customer satisfaction levels and provides guidance that outlines a technology focussed self-service system, thereby bringing customer satisfaction information to the attention of the sector in order to inform future developments.

\section{Research Question and Objectives}

Technological advancements growing rapidly in the retailing sector have enabled customers to gain access to a plethora of interaction methods with product and service providers. Therefore, the authors have outlined a research question that aims to address the factors that determine how customer satisfaction is met and increased through omni-channel marketing within the retailing industry, which is: 'What factors determine the way in which customer satisfaction is increased through Omni-channel Marketing in the retail sector?'

In the research, the authors intend to also emphasise a key focus on customer satisfaction levels and how omni-channel marketing may lead to an increase of these satisfaction levels. The rise of e-commerce means that today's consumers can now have a choice of locations for purchasing the same product. This research intends to find out what drives their satisfaction. Are influencing factors and values the same online as they are offline for consumers? The current literature around omni-channel marketing and e-commerce does not offer a clear answer to this question; therefore, outlined below are a set of research objectives which the authors intend to achieve through this study to fill this gap:

1. To review and critique the literature of omni-channel marketing and customer satisfaction in order to identify both theoretical and practical knowledge of this topic;

2. To explore how customers, perceive the use of omni-channel retailing in Next PLC and how it meets their needs in terms of customer satisfaction across a range of experiences;

3. To identify the significant influencing factors that affect customer behaviour and opinions;

4. Provide recommendations to Next PLC and future research on the topic of omni-channel customer satisfaction in terms of understanding and approach. 


\section{Literature Review}

Prior literature on the examination of customer satisfaction through omni-channel retailing is sparse, despite the fact that the use of online channels has grown rapidly over the past decade (Office for National Statistics 2019b). Therefore, this review will explore current literature around this topic and provide an insight and critical discussion into how customer satisfaction is increased through omni-channel marketing. Furthermore, this literature review will explore the impacts in which customer lifestyle is having on retail and how consumer behaviour has formed a shift in how the majority of retailers operate.

The UK retailing sector has shown a significantly high inclination towards the use of omni-channel marketing (Chen and Lamberti 2016), with current retailers such as ASOS, Amazon and eBay relying heavily on the use of online communication in order to influence purchases as this is their only marketing platform. While many retailers function solely online, retailing giants such as Next, River Island and Arcadia offer a 'bricks n clicks' approach to retailing (Herhausen et al. 2015; Hardy 2017).

\subsection{The Influence of Customer Lifestyle on Retail}

The term 'lifestyle' was introduced by Alfred Adler who defined it as a person's basic character and a way or style of living (Adler 1929). More recently, the term 'lifestyle' has also commonly been referred to as the 'patterns' in which people live or used to describe the way in which people live their lives in terms of their home, possessions, interests and where they socialise and work (Sathish and Mohan 2012). Thus, lifestyle is concerned with how people distribute time among activities (Sathish and Mohan 2012).

Whereas in recent years, the term has been significantly altered due to technological advancements gaining a vast amount of attention upon the younger demographic, more commonly known as the 'Millennials' (Bialik and Fry 2019). Consequently, technology has caused a shift and changed the way in which people are living, therefore consumers have come to realise the benefits of shopping online (Schmid and Axhausen 2019; Zhai et al. 2019), such as: saving time and energy; convenience; competitive pricing between bricks and mortar stores and online directories; broader selection of stores and items to purchase; greater access to information; access to various different stores without leaving home.

Due to work commitments, childcare or any other time-consuming activities, the use of 'Collect in Store' or 'Home Delivery' is becoming increasingly popular as this is enabling those who have time constraints to minimise time through quickly collecting an order (Jara et al. 2018). More specifically, it has been heavily researched and hypothesised that there is a higher percentage of female online shoppers than males; thus, this is significantly due to the fact that some of them work around commitments such as childcare and can shop from the comfort of their own home (Office for National Statistics 2019a; Schmid and Axhausen 2019). This can be seen in the chart below which illustrates the range of the difference in active internet users in the UK (see Table 1). However, the gap between men and women internet users is slowly closing, and what influences this trend is an interesting area that needs to be investigated.

Many studies have found that technological advancements are causing a significant impact on how customer lifestyles are beginning to influence retailing strategies (Pantano et al. 2018; Zhang and Zhao 2019). This poses a massive challenge for many retailers, especially regarding how to deliver a consistent service while simplifying the customers life as much as possible. To do this, many organisations have utilised online and mobile shopping platforms to create various interactions between the customer and the purchase of goods.

One of the most well-known strategies is omni-channel marketing, which has triggered an immense modification in the customer experience domain and has come about due to the influence of customer lifestyle and behaviour. Today, the majority of companies are abandoning the multichannel model of retailing and branching into a much more dynamic model known as omni-channel marketing, thus enabling the company to gain competitive advantage in a market by integrating, optimizing and 
increasing the reach of channels to its customer-delivering a unique and tailored experience to the customer (Lorenzo-Romero et al. 2020).

Table 1. Male and female internet users in the United Kingdom, Office for National Statistics (2019a).

\begin{tabular}{|c|c|c|c|c|c|c|}
\hline \multicolumn{7}{|c|}{ Active Internet Users in the UK (Millions) } \\
\hline & \multicolumn{3}{|c|}{ Male } & \multicolumn{3}{|c|}{ Female } \\
\hline & $\begin{array}{c}\text { Last } 3 \\
\text { Months }\end{array}$ & $\begin{array}{l}\text { More than } \\
3 \text { Months }\end{array}$ & Never & $\begin{array}{c}\text { Last } 3 \\
\text { Months }\end{array}$ & $\begin{array}{l}\text { More than } \\
3 \text { Months }\end{array}$ & Never \\
\hline 2011 & 20.039 & 0.635 & 3.645 & 19.645 & 0.789 & 5.094 \\
\hline 2012 & 20.564 & 0.648 & 3.348 & 20.2 & 0.744 & 4.773 \\
\hline 2013 & 21.242 & 0.609 & 2.89 & 21.001 & 0.666 & 4.209 \\
\hline 2014 & 21.814 & 0.546 & 2.629 & 21.643 & 0.596 & 3.81 \\
\hline 2015 & 22.229 & 0.524 & 2.462 & 22.442 & 0.598 & 3.433 \\
\hline 2016 & 22.812 & 0.435 & 2.218 & 23.105 & 0.503 & 3.097 \\
\hline 2017 & 23.2 & 0.436 & 2.013 & 23.542 & 0.492 & 2.815 \\
\hline 2018 & 23.606 & 0.401 & 1.845 & 23.954 & 0.451 & 2.614 \\
\hline 2019 & 23.875 & 0.39 & 1.639 & 24.225 & 0.417 & 2.354 \\
\hline
\end{tabular}

\subsection{The Term 'Omni-Channel' Defined}

The term 'omni-channel' is one of the most significant terms in marketing and retailing. Omni-channel is a cross channel strategy in which organisations adopt to improve their user experience (Cook 2014; Xu and Jackson 2019), and implies integration and orchestration of various shopping channels. Therefore, omni-channel can be defined as viewing the experience through the eyes of a consumer, which is orchestrated across many channels so that it is smooth, integrated and consistent (Melsted 2015). In terms of marketing, omni-channel refers to a major shift in the approach to marketing - thus, it is now important that marketers provide a seamless experience for its consumer, regardless of channel, device and location (Xu and Jackson 2019). Omni-channel marketing allows consumers to engage with a company through not only a 'bricks and clicks' approach, but through many experiences such as visiting a physical store, an online website, a catalogue, through mobile applications and social media (Hübner et al. 2016).

This omni-channel strategy brings opportunity and enjoyment to the customer experience, and enables customers to undertake the buying process through their own method and approach, which is most convenient for them (Lee et al. 2018a). Omni-channel enables the retailer to make an experience smoother, which will keep customers coming back and raise their profits (Brynjolfsson et al. 2013; Xu and Jackson 2019). Therefore, retailers are now adopting what is known as the omni-channel retailing strategy, which is one of the main topic areas for this research.

Omni-channel retailing is an e-commerce selling strategy which utilises the use of offline, online and also digital platforms such as social media, to gain competitive advantage within an industry and gain full control of a target market (Stojković et al. 2016). It allows retailers to remain competitive, due to the ever growing demand for an integrated and seamless purchasing experience for their customers (Melsted 2015).

In order to fully understand the retail and marketing sector it is necessary to recognise the terminology used to define it. Omni-channel marketing has evolved from the literature around e-commerce and embraces many digital channels and media opportunities both online and offline together with social media in order to gain competitive advantage and increase the target market (Stojković et al. 2016; Lee et al. 2018b). However, there are critics who claim the concept of omni-channel marketing is more concerned with the practice between the interaction of the customer and a combination of both online and offline channels, furthermore, this may be through the use of loyalty cards, personalised offers and even discounts, which could be seen as a form of both customer service and satisfaction (Magatef and Tomalieh 2015; Lancaster and Massingham 2018).

When it comes to customer satisfaction within omni-channel marketing, it is highlighted that it is imperative that organisations are able to expand their distribution channels in order to potentially further 
acknowledge, interact and engage in a suitable marketing mix which would allow for the identification of target markets-inevitably fulfilling customer satisfaction (Baker and Hart 2008; Herhausen et al. 2015; Jobber and Ellis-Chadwick 2016; Kotler and Armstrong 2016). Considering that the use of the internet has risen significantly over the past 5 years, and it was reported that at least $80 \%$ of the UK's population have used the internet in the past 3 months (Office for National Statistics 2019a), this significantly highlights how omni-channel retailing may in fact enable the $80 \%$ of reported users to potentially browse a retailers online directory.

There has been a significant growing trend in Europe, in the percentage of internet users by country, and it has been highlighted and recorded that the UK is the third highest internet user in Europe (Office for National Statistics 2019a). Through observing these statistics, it is apparent that online usage is at a significant high, evidencing why Next's online sales increased by $+14.8 \%$ and retail sales declined by $-7.3 \%$ (Next Retail Ltd 2018). Thus, through analysing various organisations online sales reports such as Next, H\&M and M\&S, it is evident that online retailing is one of the ways forward in terms of retailing strategy and gaining competitive advantage as sales are rapidly increasing. Therefore, the need for investigation of customer satisfaction levels in the online domain, is significant and needs to be explored.

According to previous studies, omni-channel retailing encompasses two types: 1. organisational-level studies; and 2. individual-level studies. While there is a significant amount of research into organisational level studies such as processes and practices, there is limited research into individual studies. Some of the areas explored include customer demand, purchase experience and customer convenience-all of which could fall under the topic of customer satisfaction, which in terms of e-retailing is an extremely sparse research area. Consequently, leading back to the research question of this project: what factors determine the way in which customer satisfaction is increased through omni-channel marketing in retail?

To conclude this section, research on omni channel retailing remains extremely sparse, and the majority of research is at the organisational level and does not take into account individual level factors such as customer experience and satisfaction. Taking this into consideration, it is evident that online channels are seeing a greatly increased amount of usage compared to that of 2018 (Office for National Statistics 2019a). Therefore, exploring the levels of customer satisfaction through online channels is a crucial research area that needs to be explored and could potentially broaden the research around omni-channel retailing.

\subsection{The Importance of Customer Satisfaction}

Customer satisfaction is the strategic weapon for any type of organisation (McNealy 1998). Customer satisfaction is important because product and service companies must preserve their customer resources with passion and vitality similar to us as a nation preserving our natural resources; as an organisation, our customers are our natural resource (McNealy 1998). The future for any organisation is bleak if its natural resource departs without any effort to retain them, for example the case of Nokia (McNealy 1998; Aspara et al. 2013).

This leads on to the topic of customer satisfaction, which Smith et al. (1999) state measures how well the expectations of a customer in regards to a product or service provided has been met. While there are a plethora of approaches to enhancing customer satisfaction i.e., through McCarthy's 4-P's or the Marketing Mix (Baker and Hart 2008), there is limited literature around the topic of measuring how customer satisfaction is met through the use of various online channels such as ASOS, Amazon, the Next Directory or social media platforms such as Twitter, Facebook and Instagram.

Kurata and Nam (2010) state that customer satisfaction can be maximised through the use of communication and valuing your customers and also giving prompt service and responding to feedback. However, this is in regards to a retail setting, therefore Brynjolfsson et al. (2013) have outlined the importance of using analytics and big data to better understand customer needs and wants, or in other words market push and market pull. There is no empirical research into how 
the customers themselves perceive the use of Omni-channel marketing within the retailing industry and how it brings about customer satisfaction, which is also argued by many such a Szymanski and Hise (2000) and Nisar and Prabhakar (2017) who argue the concept of 'e-satisfaction' appears crucial in the rise of e-commerce, but 'no studies have examined the factors that make consumers satisfied with their e-retailing experiences'-(Szymanski and Hise 2000, p. 310). Thus, we conclude that research around the topic of e-satisfaction is extremely sparse and unexplored.

While understanding customer satisfaction is significantly important as it strengthens the connection between an organisation and its customer base, which subsequently leads on to positive and impactful outcomes (Hill et al. 2003), there is no indication of whether you are delivering good customer service through all available channels. For example, Next which offers a Next Loves to Listen business card to its customers and also prints this on the bottom of every receipt given to customers. This offers Next the ability to measure in store customer satisfaction levels through a company-wide forum which links customers comments to their own experience. However, measuring this on their online directory is yet to be accomplished.

While there are a plethora of different methods of understanding customer reviews online, a lot of these comments, ratings and reviews do not relate to the customers' own experience of how they perceive the use of e-retailing - what satisfies them when shopping online, and why do they prefer using this channel? While this may be useful for retailers and online companies who do not possess bricks and mortar stores such as Amazon or ASOS, retailers such as Next themselves have their own online customer rating section, but understanding the overall experience of the customer's journey and how their satisfaction was increased through online shopping is extremely difficult to measure. Yes, there are options for rating items on scales of one to five on the website, but this cannot measure the data required in order to understand why customers prefer this channel and why they are abandoning original bricks and mortar stores for online retailers (Nisar and Prabhakar 2017).

Customer satisfaction is an intangible thing, and it is perishable, personal and sometimes private (Brynjolfsson et al. 2013). Therefore, measuring it on all levels is crucial to the success of an organisation, and how customers perceive the use of new integrated omni-channel retailers is crucial to the success of online retailing. Thus, measuring online customer satisfaction is a fundamental topic area that needs to be explored in which some research has already began, and can be found under the topic of 'e-satisfaction'.

\subsection{E-Satisfaction}

E-satisfaction is one of the most crucial components in determining the success of online retailing and has become one of the most frequently researched topics in marketing (Nisar and Prabhakar 2017). It provides a positive perception of the use of online products and services and this perception is vital to the long-term success of retailers such as Next, who are shifting their focus to the Omni-channel retailing strategy (Sections 2.3 and 2.4).

Unlike customer satisfaction, 'e-satisfaction' is yet to be clearly defined, however, a few definitions state that e-satisfaction reflects consumers perceptions of the use of online services and many researchers have given their perspective on E-satisfaction, for example Park and Kim (2003) who found that e-satisfaction can be influenced by factors such as user interface, website capabilities and the option to customise or tailor a shopping experience, specifically to an occasion or need (Park and Kim 2003). A more recent perspective states that it is a combination of user interface and convenience, and if convenience is continuously increased, consumers are more likely to be satisfied and reuse these capabilities (Hsu et al. 2010; Thuy 2011; Nisar and Prabhakar 2017).

From this, it is apparent that factors such as the user interface, capabilities, convenience and tailoring provided by online retailers are highly noted and recommended factors to be used when measuring e-satisfaction of online consumers, which is a crucial factor when it comes back to the research question. 
Recent research in this area expresses that price and promotion are no longer one of the main appeals when it comes to customer purchase decisions (Shirai 2015). There is a higher number of sophisticated customers who would prefer to pay a higher price to online retailers who along with their product, deliver a high quality of e-service (Zhang et al. 2014). Levels of customer satisfaction hold a significant amount of impact on loyalty, purchase intention and decision, customer retention and also have an impact on the company's performance financially (Williams and Naumann 2011; Zhang et al. 2014). Therefore, in order to build customer trust, loyalty and intention, it is imperative that e-retailers shift a higher focus onto e-satisfaction.

Researchers Azam, Qiang and Abdullah found that satisfaction is a statistically significant factor which is able to influence customer purchase intention (Azam et al. 2012). Thus, online reviews are reviewed prior to a customer purchase. Azam et al. (2012) developed measures and tested them against an online sample of 1007 respondents, concluding that all of their drivers of e-satisfaction had positive impacts on e-satisfaction. Azam et al. (2012) findings can confirm that satisfaction is a statistically significant factor influencing the consumer intention to purchase online. Results similar to this were also obtained in an earlier study by Shirai (2015), who found that online shoppers were very satisfied with convenience, product quality, value and variety.

However, while this literature is significant when it comes to understanding e-satisfaction, what this study aims to provide is an understanding of how satisfaction is increased through the use of omni-channel retailing, all activities of which are related to the introduction of both new channels and product to aid in satisfying customer demand aiming to both grasp the new market segments and build consumer loyalty (Śmigielska and Oczkowska 2017).

\section{Research Methods}

As outlined above, omni-channel marketing within the retailing sector has recently become a well-established field of research. However, the literature and evidence on how customers perceive it is sparse. Therefore, in order to identify what factors determine the way in which customer satisfaction is increased through online retailing, the authors intend to explore and critique various research methods in order to grasp a diverse amount of information on this topic in order to achieve the best result for the research area.

In this study, survey research is the specific methodology that is going to be adopted.

Survey research is a methodology which is used to gather opinions, beliefs and feelings of a selected group of individuals (Saunders et al. 2019). Encompassed within this methodology, the authors intend to adopt two research methods: 1. Questionnaires; and 2. Semi-structured interviews. The purpose of this is to gain a well-informed insight into how customer satisfaction is increased through omni-channel marketing, which will fully answer the research question at hand.

Therefore, within this research methods section, the authors present a discussion of research strategies to demonstrate awareness of the different types of methods used, followed by justification for selection and a section discussing the limitations of the chosen strategy.

\subsection{Qualitative Methods}

Qualitative research analyses use data from direct fieldwork such as observations, interviews or written documents. This type of research is concerned with analysing concrete instances in their originality or which originate from peoples expressions, activities and lifestyles in their local context (Flick 2019). Thus, qualitative research is in a position to design approaches for the social and psychological sciences and deliver concrete findings upon successful completion, and emphasises words rather than quantification in the collection and analysis of the data collected (Bryman 2016; Flick 2019).

The researchers main purpose of using qualitative methods should be derived from the direction of the research question (Flick 2019). When it comes to this specific research study, it is focusing on perspectives and opinions on the use of a new digital channel, and when researching the topic of customer satisfaction specifically there needs to be rich findings and in-depth insights into the 
phenomenon (Ahn et al. 2019). Previous research into customer satisfaction has demonstrated that the use of interviews and observations have been crucial to gaining feedback and opinions from the target audience (Bryman 2016; Saunders et al. 2019; Christina et al. 2019).

Within these research studies, the specific adopted methods of collection for qualitative data have been: 1 . interviews; 2 . focus groups; 3 . observations; and 4 . action research. The most common method being interviews, but semi-structured, as seen in the recent studies on customer satisfaction (Ahn et al. 2019; Christina et al. 2019).

Additionally, recent research into the topic of customer satisfaction has evidenced that semi-structured interviews have been a positive tool which allows for openness and depth when it comes to securing the necessary information and data from the participants, and unlike quantitative methods, allows researchers to take communication into the field (Saunders et al. 2019). This allows researchers' actions, feelings, impressions, observations and reflections to become one with the data in which they are collecting. This becomes an essential part of the data as it allows the researchers to present their own interpretation and observation of something real (Flick 2019).

However, there are some limitations to this research method. The biggest limitation is that any findings cannot be extended to wider populations of research with the same level of firmness that quantitative data can achieve (Ahn et al. 2019). This is due to the fact that the findings from the research are not tested to investigate whether they are statistically significant (Saunders et al. 2019).

This is why a lot of researchers lean towards the use of quantitative data, which is outlined below.

\subsection{Quantitative Methods}

Quantitative research is the most 'essential' approach to social research (Cooper and Schindler 2014). It enables us to experiment and support a plethora of different ideas around social reality (Creswell and Poth 2013). Quantitative research has a significant focus on numbers and statistics, and focuses on the measurements and amounts of the characteristics displayed by people or events within the research area (Thomas 2003; Cooper and Schindler 2014; Saunders et al. 2019).

The strengths of quantitative research are that it can allow us to generalise findings, explain phenomena and also enables the ability of predicting outcomes of future scenarios (Black 1999; Thomas 2003). This type of method is best adopted when you have a research question that requires the authors to describe variances in a population, for example, or measures degrees, differences or tests a hypothesis for why something has occurred (Cooper and Schindler 2014). This is due to the deep understanding and even distribution of findings across the population (Thomas 2003).

However, unlike qualitative research, quantitative uses numbers to seek out a general description or to test a casual hypothesis, and also to seek out explanations or predictions to generalise other persons or places (Thomas 2003; Creswell and Poth 2013).

\subsection{Mixed Methods}

Thirdly, there is a mixed methods approach. The debate over the relationship between both qualitative and quantitative methods has significantly shifted towards questioning research practice, for example the appropriateness of each approach or method. Thus, Rossman and Wilson (1985) states that both qualitative and quantitative methods are complementary to each other rather than competitors. This has been further justified by Greene et al. (1989) who state there are three benefits which are derived from combining both qualitative and quantitative methods: triangulation; complementarity; and development.

Furthermore, Davis et al. (2010) highlight that it is beneficial to use two approaches when conducting research as this allows research to 'produce results that are more robust and compelling than single method studies' (Davis et al. 2010, p. 6). It has been stated that the benefit of using qualitative methods is that data are more in-depth and will allow for the insight into how customers perceive digital media with more impact (Creswell and Poth 2013; Denzin 2016). Additionally, when it comes to semi-structured interviews, this will allow for 'openness', encouraging participants to open 
up on areas that were not initially planned (Twining et al. 2017). Therefore, combining these two will allow for a complementary mix which strengthens both sides of the data.

The majority of researchers focusing on the growth of omni-channel marketing and e-satisfaction have adopted a mixture of methods in order to broaden the data they collect. The most common methods have been surveys, questionnaires, semi-structured interviews and focus groups. Many benefits of this approach have been evidenced through the findings and discussions of many researchers.

\subsection{Adopted Method}

Due to the limitations outlined in both qualitative and quantitative research methods, combining them both into a mixed methods approach would eliminate the cause for limitation as all areas will be covered. Furthermore, this has also been evidenced through current research on customer service. Therefore, the two chosen methods for this research study are 1. questionnaires, and 2. semi-structured interviews.

Taking previous research on this topic into consideration through using a combination of both qualitative and quantitative data, the authors are able to utilise true and in-depth comments and identify key themes through thematic analysis, as this will be specific to Next, whereas if a single quantitative method was used, it may be applicable to all organisations in retail—which is a possible further development of this study.

\subsubsection{Questionnaire}

Questionnaires are a useful tool when it comes to collecting data. They are a very convenient approach to collecting useful comparable data from a large population. Many research studies on customer satisfaction have utilised questionnaires and seen significant results in the findings from the data (Creswell and Poth 2013).

Furthermore, the benefit of using questionnaire research is the validity and reliability of the data collected; however, this also highlights one of the main limitations of this study in that it may generate dishonest responses. While it is easy to achieve a high response rate compared to other methods, the limitation of this is that the target audience may in some way be biased and deliver dishonest responses. In order to overcome this limitation if it were to arise, the authors kept the questionnaire limited and not too lengthy, and used more generic questions that the respondent would not need to answer dishonestly.

The overall purpose of using questionnaire research within this study was that it allowed for the development of attention to areas such as behaviours, motivations, background characteristics and also demographical data, all of which are beneficial as they allow the research question of 'What factors determine the way in which customer satisfaction is increased through omni-channel marketing in retail?' to be answered fully, alongside a high level of statistical data to represent a larger portion of the population.

Additionally, questionnaires are a tool that can be mixed with other tools to create complementary results (Creswell and Poth 2013). Therefore, within this study, the authors are going to combine the questionnaire with a semi-structured interview.

\subsubsection{Semi-Structured Interviews}

Semi-structured interviews are a technique used to collect qualitative data by setting up a scenario that gives interviewees time to talk about their own feelings and opinions of a specific subject. The main purpose of the interview is decided by the authors and the objective is to understand the interviews perspective rather that giving generalisations on their behaviour (Creswell and Poth 2013). Semi-structured interviews use open-ended questions which are sometimes suggested by the authors, however, some may arise naturally during the interview. Thus, evidently, semi-structured interviews appear to be one of the most advantageous methods to utilise when it comes to gaining insight into a specific domain as it can present high validity through specific and in-depth talks in which interviewees 
can talk about something simple, and then leads onto something in more detail and in depth (Horton et al. 2004).

However, one of the major limitations of using semi-structured interviews is that their flexibility may cause the reliability and validity to be lessened (Castleberry and Nolen 2018). In order to overcome this, the authors will utilise an interview schedule, in which will be collated with key words that can be brought up during each question in order to expand and gather more data. This will also allow for observations and notes to be taken, and prevent the direction of the interview straying from the research purpose. By doing this, the meanings behind an action, for example selecting a certain answer in the questionnaire, may be revealed as the interviewee is able to speak for themselves, therefore strengthening the combination of both the questionnaire and semi-structured data and allow for significant findings.

The overall purpose of using semi-structured interviews within this study is that they allowed the authors to take observations and expand upon the questions developed. This allowed for further in-depth and meaningful data to be collected that may have been missed or undiscovered if the data was collected solely by questionnaire.

\subsection{Data Analysis}

The data collected consisted of 40 questionnaire responses and $105 \mathrm{~min}$ of audio data and observational notes. Firstly, the data collected from the questionnaires was analysed through the use of graphs an tables to illustrate the statistics and data from each question, in an attempt to evaluate how customer satisfaction is increased through omni-channel retailing. Secondly, from the semi-structured interviews, the authors generated codes and themes from the audio data relating to the interviewees understanding and opinion of shopping through their preferred method and how their satisfaction was increased or met through it. When it came to analysing the data from the semi-structured interviews, there are a plethora of techniques that could be used (Shichao et al. 2018). However, one of the most common forms of analysis within research is thematic analysis (TA), and this emphasises examining, pin pointing and recording various patterns of meaning, or themes, within the data (Braun and Clarke 2006; Shichao et al. 2018). All themes were supported by data excerpts and initial codes were generated and refined through Braun and Clarke's (2006) five-phase technique in order to produce coherent themes that were further refined to allow for the establishment of useful findings. All of the data from the interviews was transcribed, with participants given anonymity and names replaced by a pseudonym.

\subsection{Recruitment}

For the data collection, the questionnaires and semi-structured interviews were undertaken and conducted at the Stockton Teesside Park Next store. When deploying the questionnaire, there were a total of 40 respondents ( 25 female and 15 male) ranging in age from 18 to 66 years old. Upon completion of the questionnaire, respondents were requested by the authors to take part in a semi-structured interview. Seven out of the 40 respondents wanted to take part in the semi-structured interview ( 5 female and 2 male). All of the respondents and interviewees in the data collection phase were customers who had come in to collect an order they had placed online.

\section{Findings}

This chapter will present robust justification for the identity and purpose of each question used in the data collection phase, how they derived from the literature review, and will present the findings from the research conducted by the authors. Key trends and themes will be derived from the findings, which will then be analysed and discussed to generate an appropriate reference to how they support the intended purpose of the research question and literature review.

The sections below will present the data collected from the questionnaire and semi-structured interviews. The data collected from the questionnaire has been broken down into tables and graphs to 
clearly illustrate the data. For the semi-structured interviews, the audio data collected were analysed through thematic analysis, and therefore have been presented through themes and codes. Codes were generated and refined through iterative analysis to produce consistent themes that were further refined to establish useful and significant findings. These codes were then used to recode the data, which was subsequently clustered to create a thematic structure for the data. All of the data was transcribed, and interviewees were given a pseudonym for anonymity (i.e., R1, R2 etc.).

\subsection{Questionnaire}

Questionnaire responses suggest that more than half of respondents preferred shopping online $(62.5 \%)$ than traditional shopping $(47.5 \%)$. There were a total of 40 respondents, in which have been broken down by gender and age range (see Table 2). All of the questions and responses from the questionnaire are shown in Table 3, Figures 1 and 2-as well as the respective data collected from using them. For the third question, this was a written comment section and cannot be illustrated through graphs, and therefore, the information and data have been placed in a table and the key words and themes have been highlighted (see Table 4).

Table 2. Questionnaire respondents demographics.

\begin{tabular}{lcccc}
\hline \multirow{2}{*}{ Gender } & \multicolumn{5}{c}{ Age Range } \\
\cline { 2 - 5 } & $\mathbf{1 8 - 2 5}$ & $\mathbf{2 6 - 4 5}$ & $\mathbf{4 6 - 6 5}$ & $\mathbf{6 6}$ and over \\
\hline Male & 3 & 8 & 4 & 0 \\
\hline Female & 18 & 5 & 2 & 0 \\
\hline
\end{tabular}

Table 3. Key words from Question 3.

\begin{tabular}{|c|c|c|c|c|}
\hline Respondent & Key Words & Rating & $\begin{array}{l}\text { Preferred } \\
\text { Channel }\end{array}$ & Gender \\
\hline P1 & Convenience, time, cost, options, accessibility and range & Satisfied & Online & Female \\
\hline P2 & $\begin{array}{c}\text { Cost, sizing, privacy, convenience, can't try on, cannot } \\
\text { interact with item }\end{array}$ & Neutral & Online & Male \\
\hline P3 & Try on, service, instant purchase, security & $\begin{array}{c}\text { Very } \\
\text { satisfied }\end{array}$ & Retail & Male \\
\hline $\mathrm{P} 4$ & Engage with staff, try before buy & Satisfied & Retail & Male \\
\hline P5 & Scams, security, uncertainty & Unsatisfied & Online & Female \\
\hline P6 & $\begin{array}{l}\text { Options, sizing, discounts, browsing } \\
\text { time, convenience, accessibility }\end{array}$ & $\begin{array}{c}\text { Very } \\
\text { satisfied }\end{array}$ & Online & Female \\
\hline P7 & $\begin{array}{c}\text { Bad staff, limited sizes, store trade time, location, } \\
\text { parking, usability, store access, try on }\end{array}$ & $\begin{array}{c}\text { Very } \\
\text { unsatisfied }\end{array}$ & Retail & Female \\
\hline P8 & Convenience, availability of product and delivery option & Satisfied & Online & Male \\
\hline P9 & Limited sizes but available to order, try on, location & Neutral & Retail & Female \\
\hline P10 & $\begin{array}{l}\text { Options, different fits, delivery options, time, } \\
\text { accessibility }\end{array}$ & $\begin{array}{c}\text { Very } \\
\text { satisfied }\end{array}$ & Online & Male \\
\hline P11 & Cheap, options, privacy and convenience & Satisfied & Online & Female \\
\hline P12 & Convenience & Satisfied & Online & Female \\
\hline P13 & Try on, help with sizing, quality & $\begin{array}{c}\text { Very } \\
\text { satisfied }\end{array}$ & Retail & Male \\
\hline P14 & Convenience-close to work & $\begin{array}{c}\text { Very } \\
\text { satisfied }\end{array}$ & Retail & Male \\
\hline P15 & $\begin{array}{c}\text { Try on, real deal, browse with friends, experience, easy } \\
\text { return process }\end{array}$ & $\begin{array}{c}\text { Very } \\
\text { satisfied }\end{array}$ & Retail & Male \\
\hline P16 & Options and sizing & Satisfied & Online & Female \\
\hline P17 & Not many physical stores near home & Satisfied & Online & Female \\
\hline P18 & Try on different options at once & Satisfied & Retail & Male \\
\hline P19 & $\begin{array}{l}\text { Discounts, models showing stock, sizes, brands, } \\
\text { convenience, mobile phone, anytime }\end{array}$ & $\begin{array}{c}\text { Very } \\
\text { satisfied }\end{array}$ & Online & Female \\
\hline P20 & Access, personalisation, delivery options & Satisfied & Online & Female \\
\hline
\end{tabular}


Table 3. Cont

\begin{tabular}{|c|c|c|c|c|}
\hline Respondent & Key Words & Rating & $\begin{array}{l}\text { Preferred } \\
\text { Channel }\end{array}$ & Gender \\
\hline P21 & Delivery options, work 9-5, save time, at home & Satisfied & Online & Female \\
\hline P22 & Experience with product & $\begin{array}{c}\text { Very } \\
\text { satisfied }\end{array}$ & Retail & Male \\
\hline P23 & Free store delivery. & $\begin{array}{c}\text { Very } \\
\text { satisfied }\end{array}$ & Retail & Male \\
\hline P24 & Staff, prices, try on, pay for bags & Neutral & Retail & Male \\
\hline P25 & Convenience, parenting, working, fuel saving & $\begin{array}{c}\text { Very } \\
\text { satisfied }\end{array}$ & Online & Female \\
\hline P26 & Doorstep delivery, disability, usability and access & $\begin{array}{c}\text { Very } \\
\text { satisfied }\end{array}$ & Online & Female \\
\hline P27 & $\begin{array}{c}\text { Try on, experience, men's stock looks different online } \\
\text { than instore }\end{array}$ & $\begin{array}{c}\text { Very } \\
\text { satisfied }\end{array}$ & Retail & Male \\
\hline P28 & Convenience due to sizing & $\begin{array}{c}\text { Very } \\
\text { satisfied }\end{array}$ & Retail & Male \\
\hline P29 & Place in basket but then out of stock, delivery options & Neutral & Online & Female \\
\hline P30 & Decision making process i.e., formal wear & $\begin{array}{c}\text { Very } \\
\text { satisfied }\end{array}$ & Retail & Male \\
\hline P31 & Quality bad, delivery good, prices & Neutral & Online & Female \\
\hline P32 & Work time, save time, convenience & Satisfied & Online & Female \\
\hline P33 & Childcare, convenience, parenting, time, cost & Satisfied & Online & Female \\
\hline P34 & Time & Satisfied & Online & Female \\
\hline P35 & Inconvenience with children, sizing, maternity wear & Neutral & Retail & Female \\
\hline P36 & Sizing and bad customer service & Neutral & Retail & Female \\
\hline P37 & Value, convenience, time, access & Satisfied & Online & Female \\
\hline P38 & Convenience and time & Satisfied & Online & Female \\
\hline P39 & Fit around work & Satisfied & Online & Female \\
\hline P40 & Cost, options, convenience, delivery, time, access & Satisfied & Online & Female \\
\hline
\end{tabular}

Table 4. Gender and age of interviewees.

\begin{tabular}{lcccc}
\hline \multirow{2}{*}{ Gender } & \multicolumn{5}{c}{ Age Range } \\
\cline { 2 - 5 } & $\mathbf{1 8 - 2 5}$ & $\mathbf{2 6 - 4 5}$ & $\mathbf{4 6 - 6 5}$ & $\mathbf{6 6}$ and over \\
\hline Male & 1 & 1 & 0 & 0 \\
\hline Female & 3 & 1 & 1 & 0 \\
\hline
\end{tabular}

\section{1) Do you ever shop online with Next?}

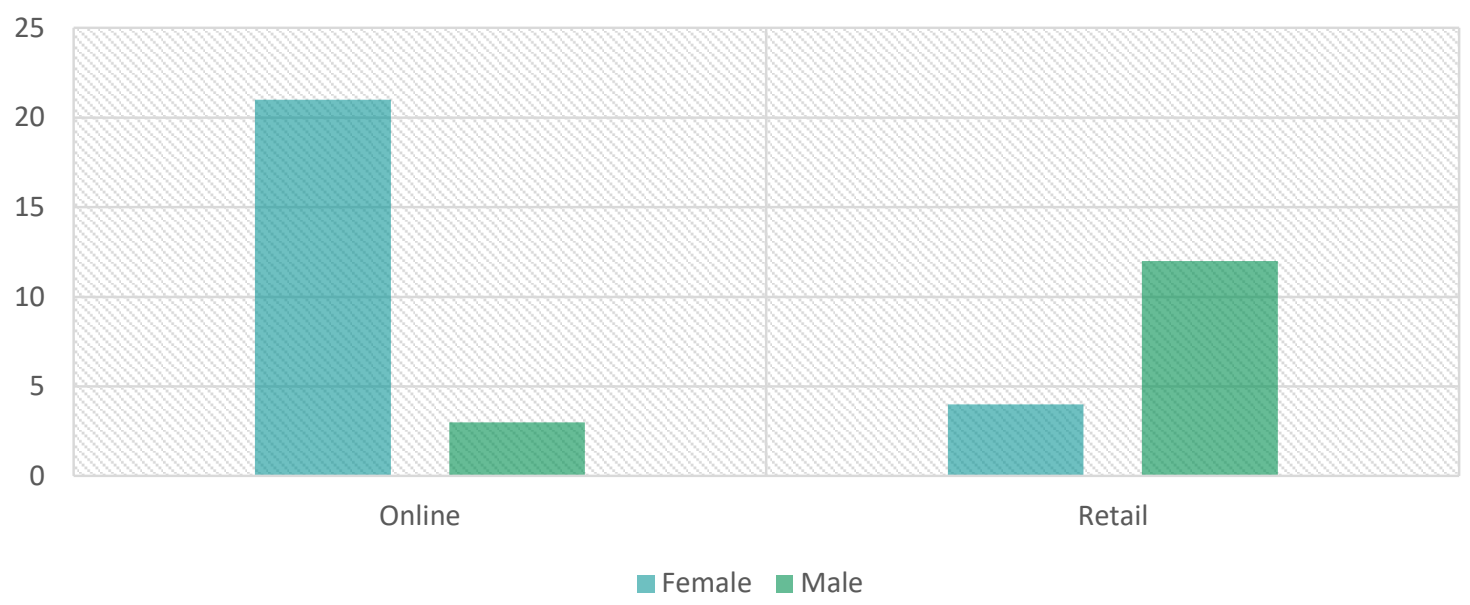

Figure 1. Demographics of respondents to Question 1 and their preferred shopping method. 


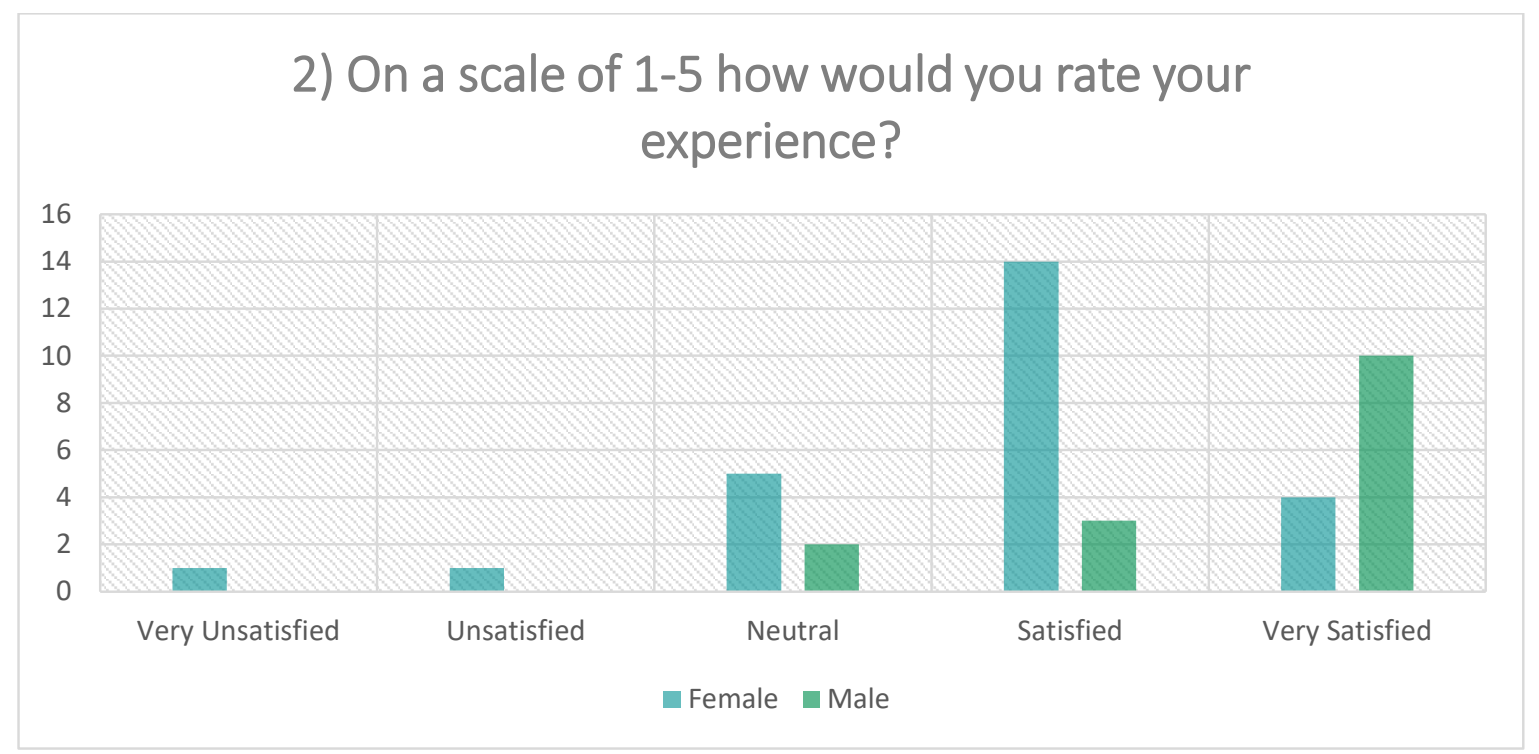

Figure 2. Responses from Question 2: On a scale of 1-5 how would you rate your experience?

\subsubsection{Question 1: Do You Ever Shop Online with Next?}

Questionnaire responses suggest that more than half of respondents preferred shopping online (62.5\%). Interestingly, $80 \%$ of male respondents showed a higher interest in shopping in retail stores, and the other $20 \%$ of male respondents preferred shopping online. Whereas, $84 \%$ of female respondents showed a higher interest in shopping online, only a mere $16 \%$ preferred shopping in the store.

Taking a look at the above statistics, the data present some very interesting findings that are supported by the literature. There is an influence of customer lifestyle on retail, as it was argued that due to parenting and working, female shoppers found shopping online more convenient and offered them flexibility around commitments; data show that lifestyle does have an impact on retail, which is a negative impact on bricks and mortar stores but a positive for online retailing, which is supported by the ever growing domain of online marketing. As the data from Question 3 show, key words such as convenience, accessibility and time are influences which had been discussed by many researchers and are clearly impacted by how we shop online. What is interesting in these findings is that there is a higher percentage of female online shoppers than male, which again relates back to the fact that due to parenting, female shoppers preferred utilising online channels for ease and of course, being able to shop from home. However, there is very limited research around the reasoning of male's preference of shopping in store. Reflecting upon the literature review, the gap between women and men online users was significantly close, however, the gap between women and men online shoppers is significantly different from the data collected in this study. This is a potential further research area that has been significantly explored in the second half of this study in the qualitative data research section where semi-structured interviews were conducted and a potential reason for this pattern has been investigated.

\subsubsection{Question 2: On a Scale of 1-5 How Would You Rate Your Experience?}

Questionnaire responses for the second question suggested that $75.5 \%$ of respondents were either satisfied or very satisfied with their experience. Specifically, $86 \%$ of male respondents were satisfied by their experience, and a further $14 \%$ felt neutral about their experience. Whereas, $72 \%$ of female respondents were satisfied by their experience, $20 \%$ felt neutral and the remaining $8 \%$ felt unsatisfied or very unsatisfied about their experience. In contrast to more males shopping in store than females, as outlined in Question 1, it is an interesting finding that no males were unsatisfied with their experience at all and the question here may be that due to male's preferring to shop in store, they have a lower expectation rate of pricing, products and the promotion of them-whereas female shoppers who have 
mainly shopped online due to commitments such as parenting, have been open to a vast domain of omni channel opportunity and thus this enabled them to have higher expectations from retail stores and the quality and pricing of product in front of them.

However, with no male respondents unsatisfied with their experience at all, this is also a potential research area for future study and has also been explored through the semi-structured interviews in this study. To investigate this question in more detail, it has been supported by Question 3: 'Please explain why you gave your experience that rating', as it breaks down key words to each individual experience and demographic.

\subsubsection{Question 3: Please Explain Why You Gave Your Experience that Rating?}

In this section of the questionnaire, respondents were given a contents box to describe and explain why they gave their experience a specific rating. In order to present this data, thematic analysis would be too in depth, therefore, key words have been extracted from the responses and grouped into a table which is outlined in Table 3. The purpose of asking this question was to ensure which method the customer used in their shopping experience and as not all respondents would want to engage in the semi-structured interview, gaining an insight into which method they used and why they rated it the level they did could provide this research with some insights that may have been missed if the whole questionnaire was just a tick box exercise.

From the collected data, it was apparent that a lot of respondents highlighted 'convenience' as the main reason for being satisfied with their shopping experience. However, what is very interesting in this finding is that when referring back to the literature, which states that male internet users were close to the same amount of female users, this evidently was not the case in regards to this study-as $80 \%$ of males preferred shopping in store and the main reason around this was for experience, fitting rooms, getting opinions from staff and trying on options. Thus, maybe due to the fact websites such as Missguided and Boohoo only deliver online and do not have retail stores, which has maybe shifted females perspective on shopping and inclined their preference to shop online with the convenience of your own home. Furthermore, from these findings it was interesting to note that key words such as 'try before you buy', 'try on' or 'experience' and 'browsing with friends' appeared to be an influence for people to hold an inclination to shop in store, preferably with males who were very satisfied with their experience-interestingly, this relates back to Question 2 where there were no unsatisfied males within the responses collected. It is apparent that male shoppers prefer shopping in store and females prefer shopping online for many reasons, and this question has highlighted a lot of findings that significantly highlight this case.

\subsection{Semi-Structured Interview}

In the following section, the authors will explore in more depth the key reasoning and influences of respondents' intentions when shopping through their preferred channel.

Out of the 40 respondents of the questionnaire, 7 were willing to take part in the semi-structured interview ( 5 female and 2 male). Each interview took around 10-15 min and in total resulted in $105 \mathrm{~min}$ of audio data, and observational notes were also taken as assistance. All interviews were transcribed, and all 7 transcripts were selected as the most relevant. Each interviewee has been given a pseudonym for anonymity (i.e., R1, R2 etc.). Interviewees' quotes will also be referenced to in the findings below, and interviewees will be referred to through their pseudonyms.

In order to narrow down and pinpoint the specific findings from the data collected, a five-phase thematic analysis was conducted in order to identify coherent themes within the data from the semi-structured interviews (Braun and Clarke 2006), these can be found below.

\subsubsection{Theme A: The Lifestyle Influence on Shopping}

When analysing the data, it was found that a significant amount of interviewees noted a sense of lifestyle influence on their preferred shopping method and when discussing why they preferred using 
the method of shopping online, associated words such as 'convenience', 'tiredness', 'busy', 'save time' or lack of product were brought up in their responses. Take R1 for example:

'... getting time to come in and browse or try things on around uni is quite difficult ... . Shopping online is more accessible for me as it is at my fingertips.'

Saving time or not having time was also expressed by another respondent, R3, who stated:

'I work offshore on the rigs, I' $m 7$ days offshore and 2 days on shore. So being able to browse while I'm away is really convenient for me as I don't have a lot of spare time to shop.'

Evidently, a lot of interviews expressed that due to lifestyle or time restrictions such as work or educational needs, shopping online is more convenient and accessible. However, some stated that stores lacked satisfactory sizing ranges for smaller or larger people. In R2's words:

'I hate trailing around stores where I know I can't get anything in my size. Shopping online gives me the opportunity to browse a lot of options which come in petite and small sizing.'

Furthermore, R4 stated that as a parent, shopping in store is quite inconvenient due to being a parent:

'So, as you can tell I have 2 children ... Coming into a shop like this is really inconvenient.'

A further inconvenience was also expressed by R5:

'Due to my wife's disability, shopping in store is really, really inconvenient for her due to blindness. Hence why I am collecting her online purchases today. Often she cannot search for items, and I can't always be here, so she feels bad for bothering staff, and useless, and in honesty, she thinks she is a nuisance.'

R4 further explains that shopping online creates higher levels of satisfaction, allows for 'freedom' and is more convenient:

'Freedom! I can explore so many options at home while I'm in bed, or when they're in bed ..... It is so convenient for new mothers or full-time mothers to shop online. It saves time, travelling inconveniences, like setting up the push chair while keeping the other one quiet. I can shop and not leave my house. This is what is really satisfying with my experience.'

Additionally, R4 continues to express that shopping online has increased satisfaction levels significantly:

'Shopping online increased my satisfaction massively. Retail websites like Next have thousands of options to browse from. And I don't even need to come into store to shop from the sale which is a massive bonus!'

These are interesting findings, as it would appear that many of the interviewees struggled to find time to shop or found it 'inconvenient' to shop in store due to parenting, education, work schedules and even disabilities. A few other interviewees stated that due to their body stature, purchasing goods from stores is quite difficult, and therefore they resort to shopping online where the product is more diverse and broken down into sections like petite or plus size.

One of the most significant findings was from an interviewee who states their partner preferred shopping online due to their disability. Thus, perhaps suggesting that shopping online increasing satisfaction levels due to avoiding inconveniences, having a hassle-free shopping experience and having a diverse range of products to shop from and even having more usability and access for those with disabilities. 


\subsubsection{Theme B: The Impact of Disability on the Shopping Experience}

It was mentioned by 2 interviewees that due to their disability, their shopping experience was impacted significantly due to a plethora of reasons. Thus, this is why they highlighted their preferred method as shopping online. A few of the key words pulled from their transcripts were 'usability', 'blindness' and 'access'.

One interviewee, R5, highlighted that due to his wife being blind, it was extremely difficult and near impossible for her to shop in store. Therefore, she preferred shopping with her husband at home on the website as he could narrow the search down by her favourite colours and style, in R5's words:

'My wife prefers for me to do her shopping for her, online. I can read what I see to her, express my opinions and let her know the colours, looks and fabrics. All of which she cannot do when shopping by herself.'

This emphasises how little current retailers have focused on delivering online and offline services for people who suffer from blindness for example.

Furthermore, R6 states that shopping in store is difficult due to store layouts and heights of merchandise:

'To be honest, I never shop in store. Today is an off chance as I am collecting a parcel (laughs) ...

The reason I don't shop in store is due to my disability. It is difficult for me to reach some merchandise as they're placed too high, and trying clothes on is extremely inconvenient for me.'

R6 goes onto discuss that due to being in a wheelchair, navigating around departments and trying to browse is difficult:

'I find it really difficult to move around departments. Sometimes the fixtures are too narrow for me to get through, and when at the checkout I can't even reach the card machine. It's quite embarrassing that I need a lot of help just to purchase a pair of shoes or pants.'

This was also expressed by R5 who stated:

'My wife finds it hard to navigate around stores alone. They are a lot of fixtures, which makes weaving in and out tiring and she can't browse properly. Often she doesn't even know is she is in the right department.'

Both interviewees provided this research with some crucial findings that could potentially strengthen the use of online shopping and how satisfaction levels could be increased from it. Due to these reasons of not wanting to shop in store, they prefer to shop online. However, shopping online is fine if you do not have sight restrictions, however in R6's case, that is impossible. Therefore, incorporating more functions and usability for disabled users is a potentially strong direction in which retailers need to investigate in order to allow for online satisfaction levels to be increased.

\subsubsection{Theme C: Incorporating Individual Preferences to Increase Customer Satisfaction Levels}

Furthermore, from the third question of the semi-structured interview 'Which functions or features of this channel did you not prefer?', many interviews expressed what they did not like, and many stated if the retailer's website could incorporate some of these functions, they would have higher satisfaction levels as this would permanently be their channel of use.

Firstly, R3 stated that:

'More personalisation and online support. As I cannot try things on while off shore, it's really hard to decide what to purchase because once I get home and don't like it, I have wasted my time considerably.' 
Additionally, R3 also discussed how not being able to approach members of staff while shopping online is a potential limitation to increasing customer satisfaction levels, therefore support such as online chat or even 3D modelling with personal characteristics could allow for satisfaction levels to be increased as the customer would not need to come into store. This was mentioned by many participants, for example R2; R3 and R4:

'Not being able to try items on. Yes the website gives information on measurements and sizing, but how accurate can these be?' (R2)

'Also, I can't approach a member of staff online like I can in store. For example making an outfit and trying it on.' (R3)

'Being able to see how clothes look for disabled people, like if they're in a wheel chair would be amazing. Not all clothing, just some. Yes, they're displaying them for the majority of people, but I do feel like clothes look different per person.' (R6)

Thus, 3D modelling or virtual reality (VR) shopping could be a potential area that would improve customer satisfaction. In R1's words:

'My needs could be satisfied more if I could tailor my outfits to my specific body shape and measurements such as height and weight, like my own personal data. I could dress myself virtually, and get an overview of what potential outfits could look like. That would be amazing.'

This was also supported by R3 who stated:

'More personalisation and online support or communication with other customers on their purchases, to understand the quality and what the real product is like.'

Furthermore, it was also suggested by interviewees that Next's website provided customers with a communication platform. Therefore, they could discuss clothing and purchases with other customers. In R7's words:

'Coming from China, we had a lot of retailers who enabled communication based interactions online. This let us communicate with existing buyers on items we wanted to buy but were hindered due to worries of quality or usability.'

R7 went onto state how a communication forum would increase satisfaction massively:

'I would prefer if I could communicate, then I would be more satisfied with what I am getting as I can kind of assess what I am getting before I get it, you know what I mean?'

This is an extremely interesting finding which could massively increase the satisfaction levels of customers. Referring back to the literature in Section 2.4 The importance of customer satisfaction, it was illustrated that many websites offer a feedback section for customers. However, being able to respond to these comments to gain a further understanding of what the product is like, could massively increase customer satisfaction levels.

\section{Discussion}

The findings from this study provide strong evidence that customer satisfaction is influenced massively by lifestyle, individual preferences, as well as website usability and capabilities. There have been three major findings from the data collected and they have been narrowed down into the following three sections. 


\subsection{The Convenience of 'Fast Moving Consumer Goods'}

Firstly, the majority of participants expressed how time and convenience were the biggest influences that made them shop online. Specifically, the participants gave many reasons for this, such as traditional bricks and mortar stores trading times not fitting around their own work times, therefore in today's digital era were more motivated and influenced to shop online as purchases can be made at anytime and anywhere. A further important finding was that due to store atmosphere, customer service or layout, customers felt uneasy as constant service was offputting and limited the customer experience due to feeling pressured. Today, we need to think about those customers who have different personalities. Not everyone wants an interaction-based experience such as speaking to staff, waiting in line or browsing items they do not need. Thus, a lot of customer lean towards shopping online as they feel satisfaction is not something that is pressured as it is when being approached by members of staff in store. However, what is interesting to note is that when males shopped in store, the data in the findings recorded that they were never unsatisfied with their experience whereas females were, thus, potentially creating the need for further research into the topic of whether females shopping preferences are impacted by the fact that online stores such as Boohoo, Missguided and ASOS are taking the competitive advantage of the retailing domain and e-satisfaction is taking over.

With the current climate of COVID-19, reflecting on R8's comments about the need for an online customer service channel is a major requirement for those who shop online. This is further supported by R7's comments who states that-'Coming from China, we had a lot of retailers who enabled communication based interactions online. This let us communicate with existing buyers on items we wanted to buy but were hindered due to worries of quality or usability.' Evidently, with the ever growing domain of online commerce and also with the current pandemic and high street retail stores lacking customers, this would appear to be the correct way to go about. This is a major finding that could potentially offer more flexibility in the online shopping experience, it would expand upon existing customer convenience. For example, as recorded by the Office for National Statistics (2020), 49\% of workers reported working at home in June 2020, with a further finding of $60 \%$ of the UK adult population currently working at home to date, during the coronavirus lockdown (Office for National Statistics 2020; Lilly 2020). This has resulted in 23.9 million British people who are working at home saving a combined $£ 1.1$ billion which many are highly likely to spend online in shopping; thus, this finding of expanding online customer service is crucial and the comments from respondents R3 and R7, alongside the fact that it is reported $26 \%$ of British people plan to continue to work from home permanently or occasionally after the global pandemic, that this is a business need for retailing organisations such as Next which is going to notice a large uplift in its online customers and in order to deliver the most exceptional service to retain the customers.

To conclude, online shopping is accessible at any time, and it is the best solution to engage customers to satisfy their needs by giving them their own shopping experience without being interrupted. Thus, they can build their shopping around work, university, parenting and their whole lifestyle. However, with the above findings and highlighting of the word convenience and current climate of COVID-19, developing a functional online customer service platform where customers can seek guidance, answers and also ask questions is absolutely necessary to allow for factors such as convenience to remain and grow. While some retailers offer a telephone customer service, these lines are shortly going to become clogged up and when working at home, there is minimal resource for staff (Pohludka and Štverková 2019). Thus, developing a system managed in the working hours of $9 \mathrm{am}-9 \mathrm{pm}$, similar to store opening times, is crucial for meeting the demand of the growing number of online shoppers. Outside of these hours, Next needs to look at building a key word search for queries which may be smaller and easy to handle by customers looking at a frequently asked questions (FAQ) page, for example. 


\subsection{Visualisation of Personal Preference}

Based on the first point made above, another important factor and influencer of customer satisfaction levels was trying clothes on. Customers dislike trying clothes on in store and this was expressed by the majority of participants, for example participant R6, who had mobility issues, or parents who brought their children as mentioned by R4-'So, as you can tell I have 2 children ... Coming into a shop like this is really inconvenient'. Thus, there are many factors which influence customers becoming unsatisfied with their experience in store and thus preferring shopping online, as noted in research by many (Kim et al. 2018), as this experience is tailored more to their specific needs and it is conveniently possible to shop at home without experiencing the above issues.

A method of overcoming this which was actually suggested by one participants would be to design and introduce a virtual fitting room. This could be through 3D modelling or VR. Therefore, this would allow customers to diversify the amount of product they can try on, with very little effort as it does not require any physical activity - they would simply need to click and browse the website and be able to tailor outfits to their own personal data and characteristics.

Furthermore, this is more convenient to allow people to build outfits quicker based on other customers' suggestions or previous purchases. This would also allow customers to browse multiple items at once, without the effort of constantly changing. It is significant to note that disabled potential customers have not been considered in this environment. Therefore, in the data visualisation, disabled customer must be considered and it is highly necessary to build a database to present those with physical disabilities the option to traditionally and virtually try on outfits too. Thus, the needs of every consumer from a range of diverse body characteristics will be met, potentially increasing customer satisfaction to a high level.

Additionally, with the current global climate of COVID-19, this portion of the shopping experience - trying items before you buy — is a very topical area due to the fact that many retailers have now closed their stores, limited the amount of customers in store and also closed fitting rooms for trying on items before purchase. Thus, highlighting the importance of the findings in R4 and R6's comments and suggestions.

To this end, in order to further customer satisfaction levels when shopping online, having recommendations based on previous purchases would a major step forward for Next, as this will influence customer purchasing decisions and, as mentioned in the findings in Section 5.1., 23.9 million British people are working at home, and have saved a combined $£ 1.1$ billion which increases the likelihood of this being spent online. Thus, building an algorithm to suggest future purchases based on prior shopping history is crucial to not only increase satisfaction levels but also the demand for income Next as a business needs during COVID-19. This algorithm could be based on for example, a theme or shopping behaviour, for example if a customer purchases a product from a range (i.e., furniture with multiple items), they could receive suggestions in the future about the same range and adding to their collection. Similarly, in terms of shopping behaviours if they are purchasing children's clothing, having future suggestions of new collections but also an algorithm taking into account child growth and suggesting larger sizes for 'convenience', a key word mentioned by many, would be useful.

Furthermore, it is also crucial to mention that in terms of ethical considerations in regards to these findings and suggestions, the safety of personal data of those shopping online is crucial. Customers who utilise the potential future of online fitting rooms may want information about their weight, height and, additionally, photographs, to be protected.

\subsection{Interactive Technology for Diversified User Experience}

Finally, like most other e-retailers, comment feedback sections really influence customer purchase intentions. However, based on participant feedback it was noted that communicating with other customers was a potential design direction that would increase customer satisfaction. For example, by creating an account-based platform to allow potential customers to engage with existing customers to gain feedback or opinions on products, this would allow customers to understand what the real 
product is like, as they could communicate with someone who has already purchased it. This is an innovation that has already been evidenced and implemented by e-retailers such as Alibaba, Taobao and Amazon, who are currently holding the competitive advantage in terms of online sales; this was a finding in the comments made by R7: 'Coming from China, we had a lot of retailers who enabled communication based interactions online. This let us communicate with existing buyers on items we wanted to buy but were hindered due to worries of quality or usability.' , furthermore, R7 went onto state how a communication forum would increase satisfaction massively: 'I would prefer if I could communicate, then I would be more satisfied with what I am getting as I can kind of assess what I am getting before I get it, you know what I mean?'.

Evidently, multiple participants have discussed the need for online communication when shopping online, whether this is in the form of speaking to customer services or even other customers who have purchased a product they are interested in. With the current global pandemic of COVID19, this is something that needs addressed, allowing for customers to further expand on their experience of omni-channel marketing.

Additionally, in regard to a specific participant who took part in this study, designing an interface for those who cannot see is a potential research area that needs to be explored. This could be through designing a tangible interface that allows visually impaired customers to browse more easily, for example if Next's website implemented voice notes on their website so that it could be navigated easier by those who are sight-impaired. While already existing screen-reading and magnifying software can make it easier for those visually impaired to browse online, there are still issues that some websites may have. For example, when browsing a text box on a website, this can be read by the software and then voiced out or translated to brail, however, when browsing an image there is no software which enables the customer to see or feel it. Therefore, designing a tangible interface for those visually impaired is a significant research area that needs to be investigated to make the use of online shopping easier, again allowing for customer satisfaction to be increased as every single customer can shop without limitation.

\section{Conclusions, Recommendations and Future Research}

In this research project, the authors outlined four key research objectives to be achieved upon completion.

Firstly, in regards to the literature review the authors aimed to review and critique the literature of omni-channel marketing and customer satisfaction in order to identify both theoretical and practical knowledge. It was stated by Jara et al. (2018) that due to work commitments, childcare and other time-consuming activities that online shopping is becoming the social norm for shopping. This was also evidenced throughout the findings collected from the data of the questionnaires and semi-structured interviews as numerous participants stated due to parenting, education and work schedules they preferred shopping online as it was more 'convenient'. Therefore the first objective was achieved upon understanding how customer satisfaction is impacted by lifestyle and based on the literature review.

Secondly, when conducting the data collection phase, exploration of how customer perceive the use of omni-channel retailing in Next and how their customer satisfaction could be met was explored. This undoubtedly meeting the second research objective. In regards to the third objective, it was apparent that identification of influential factors were discovered. This provided the research with the hypothesis that customer satisfaction levels are impacted directly by factors such as parenting, education, and work schedules. However, one of the most significant findings was that disability and visual impairments have a major impact on customer satisfaction levels as it is often difficult for them to shop online and in-store. This was missing and not highlighted in any literature reviewed or even any existing literature and research in the field of e-business and customer satisfaction.

Thirdly, in regard to the fourth academic research objective, when referring back to the research question of 'What factors determine the way in which customer satisfaction is increased through omni-channel marketing in retail?', the factors in which currently influence customer behaviour 
and how customer satisfaction can be increased are through: 1 . the convenience of 'fast-moving consumer goods'; 2 . visualisation of personal preference; and 3. augmented technology for diversified user experience.

Thus, leading onto the recommendations. Firstly, building a database that employs artificial intelligence that allows customers to achieve a more individual and tailored shopping experience is a potential recommendation for future research. This would be a relevant design direction that would allow for the findings of this research be utilised and the online consumer to be more satisfied. Additionally, a further recommendation would be how to collect the personal individual data of customers, as this is a potential limitation; therefore, it is significant to highlight that the ethics of the individual's data is the issue thus far and how to increase customer satisfaction is limited due to this.

To conclude, this study has opened an opportunity for future research into the above three factors which influence customer satisfaction and potential design insights in how to make customer experience and customer purchase intentions more successful.

Author Contributions: K.M. contributed to the design and planning of the study, the running of the interviews, analysis of the data, and the writing and revision of the manuscript. S.Z. contributed to the data analysis, and the writing and revision of the manuscript. All authors have read and agreed to the published version of the manuscript.

Funding: This research received no external funding.

Conflicts of Interest: The authors declare no conflict of interest.

\section{References}

Adler, Alfred. 1929. The Case of Miss R: The Interpretation of a Life Story. London: George Allen \& Unwin Ltd., Available online: https://archive.org/details/b29813888 (accessed on 4 August 2019).

Ahn, Jiseon, Ki-Joon Back, and Yeongbae Choe. 2019. Customers' needs satisfaction: A scale validation with refinement in the integrated resort setting. International Journal of Hospitality Management 82: 39-47. [CrossRef]

Aspara, Jaakko, Juha-Antti Lamberg, Arjo Laukia, and Henrikki Tikkanen. 2013. Corporate Business Model Transformation and Inter-Organizational Cognition: The Case of Nokia. Long Range Planning 46: 459-74. [CrossRef]

Azam, Afshan, Fu Qiang, and Muhammad Ibrahim Abdullah. 2012. E-satisfaction in Business-to-Consumer Electronic Commerce. Paper presented at the International Trade \& Academic Research Conference (ITARC), London, UK, November 7-8.

Baker, Michael, and Susan Hart. 2008. The Marketing Book. Oxford: Buttersworth-Heinmann, pp. 1-49.

Bialik, Kristen, and Richard Fry. 2019. How Millennials Compare with Prior Generations. Available online: https://www.pewsocialtrends.org/essay/millennial-life-how-young-adulthood-today-compareswith-prior-generations/ (accessed on 4 August 2019).

Black, Thomas R. 1999. Doing Quantitative Research in the Social Sciences: An Integrated Approach to Research Design, Measurement and Statistics. London: SAGE.

Braun, Virginia, and Victoria Clarke. 2006. Using thematic analysis in psychology. Qualitative Research in Psychology 3: 77-101. [CrossRef]

Bryman, Alan. 2016. Social Research Methods, 5th ed. Oxford: Oxford University Press.

Brynjolfsson, Erik, Yu Jeffrey Hu, and Mohammad S. Rahman. 2013. Competing in the age of omni-channel retailing. MIT Sloan Management Review 54: 23-29.

Castleberry, Ashley, and Amanda Nolen. 2018. Thematic analysis of qualitative research data: Is it as easy as it sounds? Currents in Pharmacy Teaching and Learning 10: 807-15. [CrossRef] [PubMed]

Christina, Chauvenet, Molly De Marco, Carolyn Barnes, and Alice S Ammerman. 2019. WIC Recipients in the Retail Environment: A Qualitative Study Assessing Customer Experience and Satisfaction. Journal of the Academy of Nutrition and Dietetics 119: 416-24.e2.

Chen, Shan, and Lucio Lamberti. 2016. Multichannel marketing: The operational construct and firms' motivation to adopt. Journal of Strategic Marketing 24: 594-616. [CrossRef]

Cook, Glenn. 2014. Customer experience in the omni-channel world and the challenges and opportunities this presents. Journal of Direct, Data and Digital Marketing Practice 15: 262-66. [CrossRef] 
Cooper, Donald R., and Pamela S. Schindler. 2014. Business Research Methods, 12th ed. Edited by Donald R. Cooper and Pamela S. Schindler. New York: McGraw-Hill Higher Education.

Creswell, John W., and Cheryl N. Poth. 2013. Qualitative Inquiry and Research Design: Choosing among Five Approaches, 3rd ed. Los Angeles: SAGE Publications.

Davis, Donna F., Susan L. Golicic, and Courtney N. Boerstler. 2010. Benefits and challenges of conducting multiple methods research in marketing. Journal of the Academy of Marketing Science 39: 467-79. [CrossRef]

Denzin, Norman. 2016. Critical Qualitative Inquiry. Qualitative Inquiry 23: 8-16. [CrossRef]

Flick, Uwe. 2019. An Introduction to Qualitative Research, 6th ed. Los Angeles: SAGE.

Goyal, Lakshmi. 2017. Leading Digital Strategy: Driving Business Growth through Effective E-commerce. Vikalpa 42: 128-30. [CrossRef]

Greene, Jennifer C., Valerie J. Caracelli, and Wendy F. Graham. 1989. Toward a Conceptual Framework for Mixed-Method Evaluation Designs. Educational Evaluation and Policy Analysis 11: 255-74. [CrossRef]

Grewal, Dhruv, Scott Motyka, and Michael Levy. 2018. The Evolution and Future of Retailing and Retailing Education. Journal of Marketing Education 40: 85-93. [CrossRef]

Hardy, Emily. 2017. Arcadia Merges Bricks and Clicks with In-Store Ordering. Retail Week. Available online: https://www.retail-week.com/technology/arcadia-merges-bricks-and-clicks-with-in-store-ordering/ 7024648. article?authent=1 (accessed on 4 October 2020).

Herhausen, Dennis, Jochen Binder, Marcus Schoegel, and Andreas Herrmann. 2015. Integrating Bricks with Clicks: Retailer-Level and Channel-Level Outcomes of Online-Offline Channel Integration. Journal of Retailing 91: 309-25. [CrossRef]

Hill, Nigel, John Brierley, and Rob MacDougall. 2003. How to Measure Customer Satisfaction, 2nd ed. Aldershot: Gower.

Horton, Joanne, Richard Macve, and Geert Struyven. 2004. Qualitative Research: Experiences in Using Semi-Structured Interviews. The Real Life Guide to Accounting Research, 339-57. [CrossRef]

Hsu, Chia-Lin, Mu-Chen Chen, Kuo-Chien Chang, and Chuang-Min Chao. 2010. Applying loss aversion to investigate service quality in logistics. International Journal of Operations E Production Management 30: 508-25. [CrossRef]

Hübner, Alexander, Johannes Wollenburg, and Andreas Holzapfel. 2016. Retail logistics in the transition from multi-channel to omni-channel. International Journal of Physical Distribution Logistics Management 46: 562-83. [CrossRef]

Jain, Shubham, and Dirk Werth. 2019. Current State of Mixed Reality Technology for Digital Retail: A Literature Review. HCI in Business, Government and Organizations. Paper presented at the 6th International Conference, HCIBGO 2019 (Held as Part of the 21st HCI International Conference), HCII 2019, Orlando, FL, USA, July 26-31.

Jara, Magali, Dany Vyt, Olivier Mevel, Thierry Morvan, and Nelida Morvan. 2018. Measuring customers benefits of click and collect. Journal of Services Marketing 32: 430-42. [CrossRef]

Jobber, David, and Fiona Ellis-Chadwick. 2016. Principles and Practice of Marketing, 8th ed. London: McGraw-Hill Education.

Kim, Hanyeong, Yun Shin Lee, and Kun Soo Park. 2018. The Psychology of Queuing for Self-Service: Reciprocity and Social Pressure. Administrative Sciences 8: 75. [CrossRef]

Kotler, Philip, and Gary Armstrong. 2016. Principles of Marketing. Harlow: Pearson Education Limited, pp. 70-83.

Kurata, Hisashi, and Seong-Hyun Nam. 2010. After-sales service competition in a supply chain: Optimization of customer satisfaction level or profit or both? International Journal of Production Economics 127: 136-46. [CrossRef]

Lancaster, Geoffrey, and Lester Massingham. 2018. Essentials of Marketing Management, 2nd ed. London: Routledge.

Lee, Liane W. Y., Tommy K. H. Chan, Alain Yee-Loong Chong, and Dimple R. Thadani. 2018a. Customer engagement through omnichannel retailing: The effects of channel integration quality. Industrial Marketing Management 77: 90-101. [CrossRef]

Lee, Liane W. Y., Yiming Tang, Leslie S. C. Yip, and Piyush Sharma. 2018b. Managing customer relationships in the emerging markets-Guanxi as a driver of Chinese customer loyalty. Journal of Business Research 86: 356-65. [CrossRef]

Lilly, Chris. 2020. Working from Home (WFH) Statistics 2020. Available online: https://www.finder.com/uk/ working-from-home-statistics (accessed on 4 October 2020). 
Lorenzo-Romero, Carlota, María-Encarnación Andrés-Martínez, and Juan-Antonio Mondéjar-Jiménez. 2020. Omnichannel in the fashion industry: A qualitative analysis from a supply-side perspective. Heliyon 6: e04198. [CrossRef]

Magatef, Sima Ghaleb, and Elham Fakhri Tomalieh. 2015. The impact of Customer loyalty programs on customer retention. International Journal of Business and Social Science 6: 78-93.

McNealy, Roderick M. 1998. Making Customer Satisfaction Happen, 1st ed. Boston: Kluwer Academic.

Melsted, Lisa R. 2015. Retailers turn to Omnichannel Strategies to Remain Competitive. Available online: http://www.forbes.com/sites/samsungbusiness/2015/02/09/retailers-turn-to-omnichannel-strategies-toremain-competitive/-4c5312ff448d (accessed on 9 August 2019).

Next Retail Ltd. 2018. Available online: https:/www.nextplc.co.uk/ \{\}/media/Files/N/Next-PLC-V2/documents/ reports-and-presentations/2018/Final\%20website\%20PDF.pdf (accessed on 4 October 2020).

Nisar, Tahir M., and Guru Prabhakar. 2017. What factors determine e-satisfaction and consumer spending in e-commerce retailing? Journal of Retailing and Consumer Services 39: 135-44. [CrossRef]

Office for National Statistics. 2019a. Internet Users, UK-Office for National Statistics. Available online: https: //www.ons.gov.uk/businessindustryandtrade/itandinternetindustry/bulletins/internetusers/2019 (accessed on 31 August 2019).

Office for National Statistics. 2019b. Retail Sales, Great Britain-Office for National Statistics. Available online: https://www.ons.gov.uk/businessindustryandtrade/retailindustry/bulletins/retailsales/april2018 (accessed on 31 August 2019).

Office for National Statistics. 2020. Coronavirus and Homeworking in the UK Labour Market: 2019, UK-Office for National Statistics. Available online: https://www.ons.gov.uk/employmentandlabourmarket/peopleinwork/ employmentandemployeetypes/articles/coronavirusandhomeworkingintheuklabourmarket/2019 (accessed on 4 October 2020).

Pantano, Eleonora, Rosanna Passavanti, Constantinos-Vasilios Priporas, and Saverino Verteramo. 2018. To what extent luxury retailing can be smart? Journal of Retailing and Consumer Services 43: 94-100. [CrossRef]

Park, Chung-Hoon, and Young-Gul Kim. 2003. Identifying key factors affecting consumer purchase behavior in an online shopping context. International Journal of Retail and Distribution Management 31: 16-29. [CrossRef]

Pohludka, Michal, and Hana Štverková. 2019. The Best Practice of CRM Implementation for Small- and Medium-Sized Enterprises. Administrative Sciences 9: 22. [CrossRef]

Qazi, Atika, Alireza Tamjidyamcholo, Ram Gopal Raj, Glenn Hardaker, and Craig Standing. 2017. Assessing consumers' satisfaction and expectations through online opinions: Expectation and disconfirmation approach. Computers in Human Behavior 75: 450-60. [CrossRef]

Rossman, Gretchen, and Bruce Wilson. 1985. Numbers and Words. Evaluation Review 9: 627-43. [CrossRef]

Ruddick, Graham. 2014. Next Profits Overtake M\&S for First Time. Telegraph. April 13. Available online: http://www.telegraph.co.uk/finance/newsbysector/retailandconsumer/10709606/Next-profits-overtakeMandS-for-first-time.html (accessed on 3 September 2020).

Sathish, Sundar, and Rajamohan Mohan. 2012. Consumer behavior and lifestyle marketing. International Journal of Marketing, Financial Services Management Research 1: 152-66.

Saunders, Mark, Philip Lewis, and Adrian Thornhill. 2019. Research Methods for Business Students, 7th ed. Harlow: Pearson Education Limited.

Schmid, Basil, and Kay W. Axhausen. 2019. In-store or online shopping of search and experience goods: A hybrid choice approach. Journal of Choice Modelling 31: 156-80. [CrossRef]

Shirai, Miyuri. 2015. Impact of "High Quality, Low Price" Appeal on Consumer Evaluations. Journal of Promotion Management 21: 776-97. [CrossRef]

Śmigielska, Grażyna, and Renata Oczkowska. 2017. Retailers' Responsibility towards Consumers and Key Drivers of Their Development in Poland. Administrative Sciences 7: 3. [CrossRef]

Smith, Amy K., Ruth N. Bolton, and Janet Wagner. 1999. A Model of Customer Satisfaction with Service Encounters Involving Failure and Recovery. Journal of Marketing Research 36: 356. [CrossRef]

Stojković, Dragan, Stipe Lovreta, and Zoran Bogetić. 2016. Multichannel strategy-The dominant approach in modern retailing. Ekonomski Anali 61: 105-27. [CrossRef]

Szymanski, David M., and Richard T. Hise. 2000. E-satisfaction: An initial examination. Journal of Retailing 76: 309-22. [CrossRef] 
Thomas, R. Murray. 2003. Blending Qualitative E Quantitative Research Methods in Theses and Dissertations. Thousand Oaks: Corwin Press.

Thuy, Pham Ngoc. 2011. Using service convenience to reduce perceived cost. Marketing Intelligence Planning 29: 473-87. [CrossRef]

Twining, Peter, Rachelle S. Heller, Miguel Nussbaum, and Chin-Chung Tsai. 2017. Some guidance on conducting and reporting qualitative studies. Computers Education 106: A1-A9. [CrossRef]

Williams, Paul, and Earl Naumann. 2011. Customer satisfaction and business performance: A firm-level analysis. Journal of Services Marketing 25: 20-32. [CrossRef]

$\mathrm{Xu}, \mathrm{Xun}$, and Jonathan E. Jackson. 2019. Investigating the influential factors of return channel loyalty in omni-channel retailing. International Journal of Production Economics 216: 118-32. [CrossRef]

Zhai, Qing, Xinyu Cao, and Feng Zhen. 2019. Relationship between Online Shopping and Store Shopping in the Shopping Process: Empirical Study for Search Goods and Experience Goods in Nanjing, China. Transportation Research Record: Journal of the Transportation Research Board. [CrossRef]

Zhang, Lini, and Haidong Zhao. 2019. Personal value vs. luxury value: What are Chinese luxury consumers shopping for when buying luxury fashion goods? Journal of Retailing and Consumer Services 51: 62-71. [CrossRef]

Zhang, Min, Lili Huang, Zhen He, and Alan G. Wang. 2014. E-service quality perceptions: An empirical analysis of the Chinese e-retailing industry. Total Quality Management Business Excellence 26: 1357-72. [CrossRef]

Shichao, Zhao, David Kirk, Simon Bowen, and Peter Wright. 2018. Enhancing the Appreciation of Traditional Chinese Painting Using Interactive Technology. Multimodal Technologies and Interaction 2: 16. [CrossRef]

Publisher's Note: MDPI stays neutral with regard to jurisdictional claims in published maps and institutional affiliations. 